\title{
Redox behaviour of selenium in sediment columns representative of the Sellafield nuclear site
}

\author{
M. S. Ho ${ }^{1}$, W. R. BOWER ${ }^{1}$, G. T. W. LAW ${ }^{1}$, K. MORRIS ${ }^{2}$ \\ ${ }^{1}$ Department of Chemistry, Radiochemistry Unit, University \\ of Helsinki, Finland. mallory.ho@helsinki.fi, \\ wrbower90@gmail.com, gareth.law@helsinki.fi \\ ${ }^{2}$ School of Earth and Environmental Sciences, University of \\ Manchester, UK. katherine.morris@manchester.ac.uk
}

Selenium is a common component of radioactive waste which will be disposed of in future geological repositories. It is also a contaminant radionuclide at nuclear sites. The mobility and availability of selenium in the environment is largely controlled by its oxidation state. Se(VI) and Se(IV) occur under oxic conditions as soluble oxyanions, selenate $\left(\mathrm{SeO}_{4}{ }^{2-}\right)$ and selenite $\left(\mathrm{SeO}_{3}{ }^{2-}\right)$, while insoluble and less toxic $\mathrm{Se}(0)$ compounds occur under reducing conditions. Due to the long half-life (7x10 years) and selenium's complex redox chemistry, various Se species can coexist in one environment, and understanding selenium's fate and behaviour is important for effective nuclear site management / radioactive waste management.

The aim of the present work was to investigate the behaviour of selenate in sediment / groundwater column systems representative of the UK Sellafield nuclear site. The impact of biostimulation treatments with acetate and lactate, across a range of groundwater compositions were examined over a period of 7 months, with spatially resolved XAS and standard geochemical techniques used to track changes in Se biogeochemistry throughout the columns. Se(VI) was present in the influent groundwater at a concentration of $5.5 \mu \mathrm{M}$. Depending on the influent groundwater chemistry (electron donor composition / sulfate concentration), Se was retained ( $>95 \%$ of added $\mathrm{Se}$ in the columns as either trigonal $\mathrm{Se}(0)$ or monoclinic $\mathrm{Se}(0)$ ). Se removal from the groundwater was faster and more complete in systems supporting more robust sulfate reduction. No evidence of sediment associated selenate, selenite or selenide was found in the column systems, and Se colloids were also not observed in the column effluents.

Surrogate column systems with identical redox chemistry and aging under bioreducing conditions were then reoxidised with aerated groundwater, or aerated saltwater. In both circumstances only limited amounts of Se were observed in the column effluents $(<5 \%)$, demonstrating that both $\mathrm{Se}(0)$ species formed during bioreduction were recalcitrant to oxidative remobilisation, and / or remobilisation due to seawater intrusion. 